\title{
Textual Presupposition: An Intertextual Account
}

\author{
Salah Mohammed Salih ${ }^{1}$ \\ ${ }^{1}$ Department of English Language, Faculty of Humanities and Social Sciences, Koya University, Kurdistan Region, Iraq
}

\begin{abstract}
Whereas there has been ample research on presupposition, and different taxonomies have been put forward on the various types of presupposition, presupposition triggers, on the difference between entailment and presupposition, and on the dichotomy semantic presupposition/pragmatic presupposition, the interrelationship between presupposition and intertextuality has not received due attention. In some philosophical and linguistic accounts, the presupposition is preserved as a meaning-based notion and thereby accounted for in non -intertextual way where only propositions that are accepted and taken for granted by speaker/ writer count. The present study argues for an intertextual account of presupposition, where the proposition is not the property of the speaker/writer per se; rather, the presupposed proposition is interpreted in terms of intertextual relations with previous texts. The aim of the present article was to find; changed to, what kind of knowledge text producers expect their audience to have to be able to process new texts; what kind of knowledge text producers presuppose in the creation of new texts; the conceptual status of presupposition when new information is conveyed; and how presuppositions obtain in the case of intertextuality. This has been accomplished by drawing on both notions: Presupposition and intertextuality to argue whereas the two notions have been kept separate in non-intertextual accounts on presupposed propositions, both notions work on the same level of drawing on the text, and therefore to argue for coining a new term textual presupposition. It has been found that it is rationally plausible to examine presupposition from an intertextual perspective, where the presupposed proposition can best be accounted for in terms of intertextual relations with previous texts, hereby, the intertextual account of presupposition has yielded a new type of presupposition, that is, textual presupposition that has not been referred to in any previous study.
\end{abstract}

KEY WORDS: Intertextuality, Presupposition, Proposition, Shared codes, Terms - Intertextual relations, Textual presupposition

\section{INTRODUCTION}

There is a naturally clear distinction between what language users presuppose and what they assert in uttering a sentence. Presupposition is one of the central concepts in pragmatics

Koya University Journal of Humanities and Social Sciences (KUJHSS),

Volume 3, Issue 1, 2020.

Received 28 April 2020; Accepted 06 June 2020,

Regular research paper: Published 16 June 2020

Corresponding author's e-mail: salah.mohammed@koyauniversity Copyright (C2020 Salah M. Salih. This is an open access article distributed under the Creative Commons Attribution License.
There is, however, a lack of agreement among philosophers, linguist, and scholars on what constitutes a presupposition, and what types it subsumes. Presupposition is the process whereby speakers linguistically mark the information that is presupposed or taken for granted, rather than being part of the main propositional content of an utterance. There have been a variety of definitions and types. In pragmatic theory, presupposition is analyzed involving attitudes and knowledge of language users. Broadly, presupposition is a type of inference associated with utterances of naturallanguage sentences.

In general, a presupposition is an inherent property of human language use. It is fundamentally hard to find a sentence that does not imply some assumption and thereby is it impossible for a sentence to be without a 
presupposition. Presupposition is often contrasted with the term "assertion," "which refers to the act of getting across one's meanings in an overt manner; however, all assertions, even the simplest, will themselves contain presuppositions of some kind." Thus, "presuppositions have the professed use of enabling language users to be economical" (Bekalu, 2006, p. 153).

Presupposition is different from other inference types in that the former generally conveys background, uncontroversial information with respect to the context of utterance. For example, the utterance: Tony forgot to call Rachel, typically leads to two presuppositions: (1) Tony was supposed to call Rachel and (2) John did not call Mary. The presuppositions of an utterance are already known to be true and thereby accepted by the speech event participants, or, at least, the speaker assumes so when the utterance is made.

Intertextuality is one of the most commonly used and misused terms in the contemporary critical vocabulary. It is assumed that intertextuality is a term that is generally understood and provides a stable set of critical procedures for interpretation (Allen, 2000, pp. 1-2). The notion of intertextuality emphasizes that "...to read is to place a work in a discursive space, relating it to other texts and to the codes of that space, and writing itself is a similar activity: A taking up a position in a discursive place (Culler, 1976, pp. 1382-1383).

According to Hiramoto and Park, this intertextual perspective is "...crucial for our understanding of how media representations of speakers and languages shape many of our preconceptions of others" (2010, p. 179). Presupposition represents propositions that are taken by the producer of the text as already established or given, and "there are many formal cues in the surface organization of the text to show this.

Some accounts of presupposition treat them in a nonintertextual way as only propositions that are given and taken for granted by text producer" (Fairclough, 1992, pp. 120-121).

Some accounts of presupposition treat them in a nonintertextual way as only propositions that are given and taken for granted by text producer" (Fairclough, 1992, pp. 120-121).

In some philosophical and linguistic accounts, the presupposition is preserved as a meaning-based notion and thereby accounted for in non-intertextual way where only propositions that are accepted and taken for granted by speaker/writer. The present study argues for an intertextual account of presupposition, where the proposition is not the property of the speaker/writer; rather, the presupposed proposition is interpreted in terms of intertextual relations with previous texts

The aim of the present article was to find; changed to, what kind of knowledge text producers expect their audience to have to be able to process new texts; what kind of knowledge text producers presuppose in the creation of new texts; the conceptual status of presupposition when new information is conveyed; and how presuppositions obtain in the case of intertextuality. This will be accomplished by drawing on both notions: Presupposition and intertextuality to argue that whereas the two notions have been kept separate in accounts on presupposed propositions, both notions work on the same level of drawing on the text, and therefore to argue for coining a new term textual presupposition.

The interrelationship between the two notions, presupposition and intertextuality will be scrutinized to argue that an intertextual account of presupposition, where the proposition is not the property of the speaker/writer; rather, the presupposed proposition is interpreted in terms of intertextual relations with previous texts.

\section{PRESUPPOSITION}

Presupposition is the relationship between two propositions in which the second is the implicit presumption of the first. Hudson (1999, p. 321) defines presupposition as "something assumed (presupposed) to be true in a sentence which assets other information." Besides, Widdowson and Yule (1996, p.26) stated that the concept of presupposition is often treated as the relationship between two propositions. According to Yule (1996, p. 133), linguistic messages are designed on the basis of large-scale assumptions about "...what our listeners already know. Some of these assumptions may be mistaken, of course, but mostly they are appropriate. What a speaker (or writer) assumes is true or known by a listener (or reader) can be described as a presupposition." Moreover, Yule defines presupposition as: A presupposition is something the speaker assumes to be the case before making an utterance (1996, p. 25).

According to Jef Verschueren, presuppositions are "relations between a form of expression and an implicit meaning which can be arrived at by a process of (pragmatic) inference." The presupposition is "an implicit meaning that must be presupposed, understood, taken for granted for an utterance to make sense." (1999, p. 30). On the other hand, Lambrecht regards presuppositions as "a lexicogrammatical phenomenon that belongs to the information mutually known on the part of interlocutors in conversational exchange." Hence, he defines presupposition as "the set of propositions lexicogrammatically evoked in a sentence which the speaker assumes the hearers already know or is ready to take for granted at the time of speech" (1994, p. 52).

The term presupposition first appeared in the work of the German philosopher Gottlob Frege (1892) in his writings on the nature of reference and referring 
expressions. Kadmon (2001, p. 10) summarizes Frege's main claims as follows:

- Reference expressions (names, definite descriptions) carry the presupposition that they do in fact refer.

- For a sentence to have a truth value, its presupposition must hold.

- A presupposition of a sentence is also a presupposition of its negation.

\section{A. Presupposition Types}

In the discussion of how speakers' assumptions are formulated, Yule (1996, pp27-32) provides a taxonomy of presupposition into seven types:

\section{Potential presupposition}

A potential presupposition is "an assumption typically associated with the use of a linguistic form (words, phrases, and structure)." He further divided potential presupposition into six categories.

\section{Existential presupposition}

It is the assumption assumed to be committed to the existence of the entities' names by the speaker and assumed to be present in the noun phrase. That is, these presuppositions are the aspects of meaning that must be known previously. They are taken for granted by the interlocutors and necessary to be understood properly by them to interpret an utterance.

Yule (1996, p. 27) states that the possessive constructions in English are associated with a presupposition of existence. It is assumed to be present in any definite noun phrase, as well. For instance:

Mary's cat. $\rightarrow$ Mary has a cat.

Your car-» you have a car.

My mother's dress is dirty -» my mother exists and that

she has a dress.

Frege's discussion regarding the nature of presupposition is about reference and how to translate referring expressions into a logical form. If anything is asserted there is always an obvious presupposition that the simple or compound proper names used have a reference. If one therefore asserts:

Kepler died in misery -» The name Kepler designates

something.

Thus, there is a presupposition that the name "Kepler" designates something. Hence, proper names in a sentence carry the presupposition that they designate something in the world

- that it exists. Frege concluded that the presupposition is not part of the descriptive meaning of the sentence, that is, its literal meaning. He further observed that presuppositions are preserved under negation. Therefore, If $\mathrm{p}>\mathrm{q}$, then $\mathrm{p} \gg \mathrm{q}$

Kepler did not die in misery -» The name Kepler

designates something.

\section{Factive presupposition}

It is the assumption that is held true and that can be identified by some verbs such as "know," "realize," "regret," "be," "aware," "odd," and "glad." The use of particular expression by the speaker is taken to presuppose the truth of the information that is stated after it. Yule (1996, p. 27) argues that the information that follows verbs such as know, realize, regret as well as phrases containing a form of "be" with "aware" and adjectives such as odd and glad, is treated as a fact and such fact is labeled as factive presupposition. For examples:

Michael didn't realize that Cano was wrong $\rightarrow$ Cano was wrong

Linda regrets telling us $\rightarrow$ Linda told us

Rachel is glad that it is over $\rightarrow$ It is over

Fred didn't realize that he insulted his boss. $\rightarrow$ Fred

insulted his boss

He isn't aware that he missed an opportunity. $-\gg \mathrm{He}$

missed an opportunity.

Lexical presupposition

It is the presupposition that is carried by lexical items such as manage, stop, start, and again. These are the forms that are treated as sources of lexical presupposition. Yule (1996, p. 28) states in lexical presupposition, a particular expression used by the speaker is taken to presuppose another concept. For examples:

She stopped smoking $\rightarrow$ he used to smoke

They start complaining -» they weren't complaining

before You're late again $\rightarrow$ you are late before

He managed to reach in time. -» He reached in time.

According to Kempson (1975, p. 63), in the case of lexical items, its presuppositions are said to be those elements of its meaning which are unaffected by negation. To simplify, these are the elements of meaning which are undeniable. For instance:

She didn't stop gossiping. - $\rightarrow$ She used to gossip.

\section{Structural presupposition}

There are certain presuppositions which are associated with sentence structure. It is the assumption associated with the use of certain words and phrase and assumed to be true, for example, WH question construction in English is conventionally interpreted with the presupposition that the information after the WH-form is already known to be case.

As Yule (1996, p. 28) analyses it, some structures have been traditionally analyzed as presupposing that part of the structure which is already assumed to be true. Such structures are used to treat the message as presupposed and hence to be accepted as true by listeners. Such structures include WHconstructions. WH question is conventionally interpreted with the presupposition that information after $\mathrm{WH}$-word is always a fact. When speaker asks such questions, it is presupposed that the listener has accepted the truth of the presupposition. Such presuppositions deal with the ways of presenting information that the speaker believes what the listener should believe. For examples:

Where did you buy the bike? -» you bought the bike
Why did John kill the snake? -» John killed the snake

When did you get Master's Degree? -» You got Master's Degree. 


\section{Non-factive presupposition}

Non-factive presuppositions are associated with a number of verbs in English. It is the assumption that is assumed not to be true and which is identified by presence of some verb such as "dream," "image," and "pretend." Those are used with presupposition that what is not true. Yule (1996, p. 29) states that in contrast with the presuppositions assumed to be true, non-factive presuppositions are assumed not to be true. Verbs such as dream, imagine, and pretend are followed by such type of presuppositions. For examples:

\section{I dream that I was rich $\rightarrow$ I was not rich}

We imagine that we were in Hawaii -» you are not in

Hawaii He pretends to be ill-» he is not ill

\section{Counterfactual presupposition}

Counterfactual presuppositions imply the meaning that what is presupposed is not only "not true" but it is "opposite of what is true" or contrasting the facts. In general, counterfactual conditionals presuppose that the information in if-clause is not true at a specific time. For instance, some conditional structure, generally called counterfactual conditionals, presuppose that the information in if-clause is not at the time of utterances. For instance:

If Smith were Mary's boss, he would have punished her. -

"Smith is not Mary's boss.

If English were our mother tongue, we would have acquired it as the first language. - English is not our mother tongue.

Some other presupposition types have been provided by different language philosophers and linguists. These include semantic, pragmatic, actual, categorical, sentential, utterance, and speaker's presupposition.

\section{Semantic presupposition}

In semantics, the presupposition is studied with reference to the truth-conditional aspects of meaning. Attempts to formulate the semantic theories of presupposition, as Levinson (1983, p. 199) argues, are largely misplaced. Levinson defines semantic presupposition as: A sentence (A) semantically presupposes another sentence B iff:

a. In all situations where $\mathrm{A}$ is true, $\mathrm{B}$ is true

b. In all situations where $\mathrm{A}$ is false, $\mathrm{B}$ is true.

Truth-conditional theories of presupposition treat it as a special species of entailment, namely, one in which a logical consequence relation can be defined in such a way that it is affected by negation. As a result, semantic presupposition remains a kind of invariant relation. Levinson states: Semantics on this view is concerned with the contextindependent, stable meaning of words and sentences, leaving to pragmatics those inferences that are special to certain contexts. Given this much, it is clear that presupposition belongs in pragmatics and not in semantics (Ibid, p. 200).

\section{Pragmatic presupposition}

From the 1970s onward, it became widespread that the difference between presupposition and other semantic relations is that of context-sensitivity. Thus, semantic theories of presupposition were incapable of analyzing presupposition independently. Consequently, such semantic theories of presupposition have been deserted, paving ways to pragmatic presupposition. Levinson defines pragmatic presupposition as: An utterance A pragmatically presupposes a proposition $\mathrm{P}$ iff $\mathrm{A}$ is appropriate only if $\mathrm{B}$ is mutually known by participants (ibid, p. 205).

\section{Actual presupposition}

An actual presupposition is any potential presupposition that is not canceled by its context. As Levinson (1983, p. 13) points out, canceling mechanism separates certain presuppositions from those that survive and become actual presuppositions. He further states that potential presuppositions are associated with sentences, whereas actual presuppositions are associated with utterances. For instance, an utterance like the following has two potential presuppositions. For example:

Martin told that the Queen of England is tall. -» There is someone called as Martin. -» There is a Queen of England.

Out of these two presuppositions, only the first one is an actual presupposition and the second one carries information that is reported.

\section{Categorical presupposition}

Categorical (or sortal) presuppositions are related to the domain of predicates. Consider the following example from Allwood et al. (1977, p. 151):

Fafnir is clever.

The Eiffel Tower is clever.

The first sentence is true, but the second is neither true nor false. The predicate be clever could be said to presuppose that its subject is a living being. Allwood et al. described such cases to illustrate the concept of domain for predicates. The domain of a predicate is a set of all the things to which it can be meaningfully attributed. The subjects of such predicates exist as a restriction on the domain of the predicate.

\section{Sentential presupposition}

A sentence presupposes $\mathrm{P}$ iff normal utterances of $\mathrm{S}$ presuppose P. Soames (1982, pp. 85-86) attempts to describe the linguistic notion of sentential presupposition with reference to the notion of utterance presupposition, which in turn is directly related to the pragmatic notion of speaker's presupposition.

\section{Utterance presupposition}

Utterance Presupposition an Utterance U presupposes $\mathrm{P}$ (at t) iff one can reasonably infer from $U$ that the speaker $S$ accepts $\mathrm{P}$ and regard it as uncontroversial, either because

a. $\mathrm{S}$ thinks that it is already part of the conversational context at $t$, or because

b. $\mathrm{S}$ thinks that the audience is prepared to add it, without objection, to the context against which $\mathrm{U}$ is evaluated.

\section{Speaker's presupposition}

In the case of speaker's presupposition, a member $\mathrm{S}$ of a conversation presupposes a proposition $\mathrm{P}$ at the time $\mathrm{T}$ iff, at $\mathrm{T}, \mathrm{S}$ believes, or assumes (a) P; (b) that the other members of the conversation also believe or assume $\mathrm{P}$; and (c) that the other members of the conversation recognize that $S$ believes or assumes (a) and (b).

The above discussion has reflected on the taxonomies and types of presupposition in the literature. It is evident that 
language philosophers and linguists have so far provided 14 presupposition types. These categorizations of types have been made based on the background/shared information that is taken for granted and that obtains between the speaker/ writer and hearer/reader. In what follows, the notion of intertextuality will be explained, paving the way for the relationship between presupposition and intertextuality.

\section{INTERTEXTUALITY}

Intertextuality refers to the interdependence whereby texts stand in relation to one another to yield propositions. Texts, in this conception, do build on, draw from, or even evoke other texts. Intertextuality as a notion is not new; it has long been recognized as the study of how texts affect one another (Moyise, 2002, p. 418). However, intertextuality, as a term, was coined by Julia Kristeva and introduced into the literary discussion in 1969. According to Kristeva intertextuality refers to the various connections in form and content that link a text to other texts; that is, each text exists in relation to other texts.

In other words, intertextuality is a "textual interaction produced within the text itself" that can designate "how the text reads history and locates itself in it" (1969, p. 443). She speaks of texts in terms of two axes; one is a "horizontal axis" linking the creator and audience of a text whereas the other is a "vertical axis" which links the text to other texts (1980, p. 69). "These two axes are connected through shared codes across time and space", that is, "every text and every meaning depends on preexisting codes.

For Fairclough (1992, p. 84), intertextuality is basically "the property texts have of being full of snatches of other texts, which may be explicitly demarcated or merged in, and which the text may assimilate, contradict, ironically echo, and so forth."

Moreover, intertextuality, according to De Beaugrande and Dressler (1992, p. 182), is one among seven standards that define what a text. A text is considered to be a communicative occurrence only if it meets the standard of intertextuality which is one of the standards of textuality. Intertextuality subsumes "...the ways in which the production and reception of a given text depend on the participants' knowledge of other texts." They assert that the process of intertextuality in text type and text allusion is conducted by a process of "mediation." which is "the extent to which one feeds one's goals and beliefs into the model of the communicative situation." The greater the mediation, "the more the expense of time and processing activities between the use of the current text and the earlier encountered texts." Mediation is great in "...the development and the use of text types. Mediation is smaller with the using quotation or to refer to well-known texts such as famous speeches or works of literature" (Ibid).

For Porter (1986, p. 34), the principle of intertextuality maintains that "all writing, speech, and signs arise from a single network; what Vygotsky called the web of meaning." On the relation between text and intertext, however, Plett
(1991, pp. 5-6) makes clear that "all intertexts are texts. Yet this equation does not work with a reverse state; this implies that not all texts are intertexts." Moreover, whereas text is autonomous, that is, it has no relations with other texts, "intertext has relations with other text. It exchanges its internal coherence entirely for an external one. It relinquishes its identity and disintegrates into various text particles that only bear an external reference."

On the levels of intertextuality, Bazerman (2004, pp. 86-88) distinguishes different levels based on how a text evokes or depends on other texts. A text may draw on earlier texts as a meaning source; a text may draw on the social dramas of former texts involved in the discussion; a text may explicitly use other expressions such as background, support, and contrast; a text may less explicitly depends on beliefs, problems, ideas, and statements generally circulated; every text evokes certain social worlds using implicitly distinct types of language, phrasing, and genres; a text depends on the available resources of language using language and language forms without having attention to the intertext.

In the subsequent sections, the relationship between presupposition and intertextuality will be discussed to explicate the notion of textual presupposition.

\section{PRESUPPOSITION AND INTERTEXTUALITY}

The notion of presupposition has originated within philosophy and ultimately acquired a substantial prominence in the non-conventional study of meaning, as an implicit assumption about the world or background belief relating to an utterance whose truth is taken for granted in discourse. Intertextuality, on the other hand, refers to the various connections in form and content that link a text to other texts. That is, texts are interconnected in terms of two axes; horizontal axis and a vertical axis. These two axes correlate and coincide in terms of shared codes across time and space. Thus, every meaning depends on preexisting codes.

This section involves a new line of account on the presupposed proposition that departs the conventional notion of presupposed proposition. In terms of intertextuality, the presupposed proposition is no longer the property of the text producer; the presupposed proposition is the property of textual relations and the interrelations among present and previous texts.

The aim is to draw on both notions: Presupposition and intertextuality to argue that whereas the two notions have been kept separate in accounts on presupposed propositions, it is rational to perceive of these two notions as drawing on the same source (text) and to argue again for the fusion of the two notions to coin a new term, textual presupposition, that will embrace both notions.

A line of support for this argument comes from Porter (1986), wherein his categorization of intertextuality; he shifts attention of intertextuality from the writer/speaker as individual to the source and social contexts from which the discourse of the author arises. According to this view, two 
types of intertextuality can be distinguished: Iterability and presupposition (pp. 34-35). The latter refers to "assumptions made by the text about its referent, its context, and its readers to portions of the text that are read, but which are not explicitly "there." He further asserts that "texts not only refer to but in fact contain other texts" (Ibid, p. 36).

Another line of support for this argument can be found in Fairclough's (1992), where he isolates five forms of intertextuality and four techniques constitute intertextuality. These forms include discourse representation, presupposition, negation, metadiscourse, and irony (pp. 118, 124). According to Fairclough, some accounts of presupposition treat them in a non-intertextual way, and thus, only text producers' propositions count. Based on the previous discussion, an intertextual account of presupposition, where the presupposed proposition does constitute information taken for granted by writer/speaker, can best be accounted for in terms of intertextual relations with previous texts. Moreover, in the same account, even the presupposed proposition, that is taken for granted as the property of the text producer, can be interpreted in terms of intertextual relations with previous texts.

A third line of support comes from Culler 1976 where he finds that the notion of presupposition, "which is not defined in terms of the speaker's or author's beliefs, introduces modest intertextuality relating sentences of a text to another set of sentences which they presuppose" (Culler, 1976, p. 1389).

Moreover, metatextuality as one type of intertextuality serves to support the intertextual account of presupposition as metatextuality unites a given text to another. Metatextuality is "a text that takes up a relation to critical commentary to another text" (Al-Dulaimi and Dawood, 2014, p. 61). Metatextuality entails that references to other texts are not stated; they are implied and thus understood in the text at hand (Simandan, 2010, p. 32).

Based on the above discussion, it is evident that whereas presupposition and intertextuality have to a large extent been kept separate, it is logical to argue that both notions work on the same level of drawing from the text. Therefore, the two notions can be fused in an attempt to coin a new term textual presupposition. In this sense, textual presupposition can be defined as presupposed propositions that are drawn from the text relations rather than from the information conveyed by the text producer.

This new type of presupposition, textual presupposition, is there whenever and wherever the conveyed presupposed proposition is not the property of the text produced. Moreover, even in cases where the presupposed proposition is perceived of as the property of the text producer, it is rational and even more plausible to perceive of it as the result of intertextual relations that obtain among the texts.

\section{Conclusions}

This paper has involved a new line of account on presupposed propositions. This new line of account departs the conventional account of presupposition and argues for an intertextual account.
Presupposition has been preserved as a meaning-based notion and thereby accounted for in a non-intertextual way where only propositions that are accepted and taken for granted to be the property of the speaker/writer.

Moreover, whereas the previous philosophical and linguistic accounts on both presupposition and intertextuality have kept the two notions separate in accounts on presupposed propositions, it has been found that it is better and more plausible to examine these presupposed propositions from an intertextual perspective.

It has been found that it is rational to examine presupposition from an intertextual perspective, where the presupposed proposition that used to be taken for granted as the property of the text producer can best be accounted for in terms of intertextual relations with previous texts, hereby, the intertextual account of presupposition has yielded a new type of presupposition, that is, textual presupposition that has not been referred to in any previous study.

It has also been found that in terms of the new intertextual account, the two notions, presupposition and intertextuality both work on the same level of drawing on the text and that the presupposed proposition is no longer the property of the text producer; the presupposed proposition is the property of textual relations and the interrelations among present and previous texts.

\section{REFERENCES}

Al-Dulaimi, A.S. and Dawood, O.A. (2014) An analytic study of james joyce's "eveline" in the perspective of intertextuality. Tikrit Uni Journal for Humanities, 21(1), pp. 52-81.

Allen, G. (2000) Intertextuality. London: Taylor and Francis.

Allwood, J., Andersson, L.G. and Dahl, O. (1977) Logic in linguistics. Cambridge: Cambridge University Press.

Bazerman, C. (2004) Intertextuality: How texts rely on other texts. In: Bazerman,

C. and Prior, P.A., (eds.), What writing does and how it does it: An introduction to analyzing texts and textual practices. United States: Lawrence Erlbaum Associates, pp. 83-96.

Bekalu, M.A. (2006) Presupposition in news discourse: Discourse and Society, 17(2), pp. 147-172.

Culler, J. (1976) Presupposition and intertextuality. MLN. Comparative Literature, 91(6), pp. 1380-1396.

De Beaugrande, R.A. and Dressler, W.U. (1992) Introduction to text linguistics. New York: Longman.

Fairclough, N. (1992) Discourse and social change. Cambridge, UK: Polity Press.

Frege, G. (1892) On Sense and Reference". Philosophie, 16, pp. 192-205.

Filippo, D. (2016) Introduction: Presuppositions philosophy, linguistics and psychology. Topoi, 35(1), pp. 5-8.

Hiramoto, M. and Sung- Yul, P.J. (2010) Media intertextualities: Semiotic mediation across time and space. Pragmatics and Society, 1:2, pp. 179-188.

Hudson, G. (1999) Essential introductory linguistics. United Kingdom: Blackwell Publishers. 
Kadmon, N. (2001) Formal pragmatics semantics, pragmatics, presupposition, and focus. Journal of Pragmatics, 37, pp. 749755.

Kempson, R.M. (1975) Presupposition and the delimitation of semantics. Cambridge: Cambridge University Press.

Kristeva, J. (1969) Narration et transformation. Semiotica, 1(4), pp. 422448.

Kristeva, J. (1980) Desire in language: A semiotic approach to literature and art. New York: Columbia University Press.

Lambrecht, K. (1994) Cambridge studies in linguistics. Information structure and sentence form: Topics, focus, and the mental representations of discourse referents.New York, US: Cambridge University Press.

Levinson, S.C. (1983) Pragmatics. Cambridge: Cambridge University Press.

Moyise, S. (2002) Intertextuality and biblical studies: A review. Verbum et Ecclesia, 23(2), pp. 418-431.

Plett, H.F. (1991) Intertextualities. In: Plett, H.F., (ed.), Intertextuality. Berlin amd New York: Walter de Gruyter, pp. 3-29.

Porter, J.E. (1986) Intertextuality and the discourse community. Rhetoric Review, 5(1), pp. 34-47.

Simandan, V.M. (2010) The matrix and the alice books. Raleigh: Lulu Books.

Soames, S. (1982) How presuppositions are inherited: A solution to the projection problem Linguistic Inquiry, 13, pp. 483-545.

Verschueren, J. (1999) Understanding pragmatics. New York: Edward Arnold.

Widdowson, H.G. and Yule, G. (1996) Pragmatics. 4th ed. Oxford: OUP, USA.

Yule, G. (1996) Pragmatics. Oxford, New York: Oxford Universityn Press. 